La revue La revue pour l'histoire du CNRS

POUR L'HISTOIRE DU CNRS $17 \mid 2007$

Objectif biotechs?

\title{
La ville insoutenable
}

Antonin Berque, Philippe Bonnin, Cynthia Ghorra-Gobin (dir.). Belin, 2006

Hélène Harter

\section{OpenEdition}

Journals

Édition électronique

URL : https://journals.openedition.org/histoire-cnrs/2200

DOI : 10.4000/histoire-cnrs.2200

ISSN : 1955-2408

Éditeur

CNRS Éditions

Édition imprimée

Date de publication : 3 juillet 2007

ISBN : 978-2-271-06558-2

ISSN : 1298-9800

\section{Référence électronique}

Hélène Harter, « La ville insoutenable », La revue pour l'histoire du CNRS [En ligne], 17 | 2007, mis en ligne le 03 juillet 2007, consulté le 20 mai 2021. URL : http://journals.openedition.org/histoire-cnrs/ 2200 ; DOI : https://doi.org/10.4000/histoire-cnrs.2200

Ce document a été généré automatiquement le 20 mai 2021.

Comité pour l'histoire du CNRS 


\title{
La ville insoutenable
}

\author{
Antonin Berque, Philippe Bonnin, Cynthia Ghorra-Gobin (dir.). Belin, \\ 2006
}

\section{Hélène Harter}

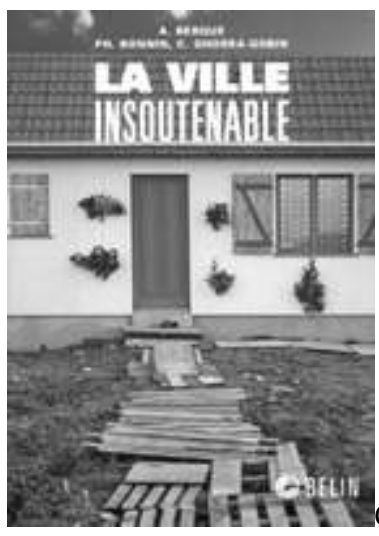

Cet ouvrage est issu du colloque « Les trois sources de la villecampagne » qu'ont organisé Antonin Berque, Philippe Bonnin et Cynthia Ghorra-Gobin au Centre culturel international de Cerisy en septembre 2004. Partant du constat d'un gaspillage des ressources incompatible avec les équilibres de la biosphère, les auteurs développent le concept d'habitat urbain insoutenable. Ils abordent cette question à travers l'effacement de la distinction historique entre ville et campagne et la recherche en ville d'une dimension rurale idéalisée qui donne naissance à la "ville-campagne ". Le propos est original d'autant que l'approche est pluridisciplinaire, diachronique et comparative. Il s'agit de traiter de l'Europe occidentale, de l'Amérique du Nord et de l'Asie orientale grâce aux travaux de chercheurs venant de ces trois aires géographiques.

1 Comment expliquer l'engouement pour la «ville-campagne »? Philippe Bonnin expose la force du mythe arcadien en Europe occidentale tandis que Brice Gruet s'intéresse à la villa romaine. Comme le montre Augustin Berque, la Chine connaît avec le Grand Même et l'ermitage paysager l'équivalent de la pastorale gréco-latine. Ce modèle très esthétique, dont les paysans sont absents, gagne toute l'Asie orientale. Les pavillons de thé japonais tout comme les poèmes du coréen Yun Sondǒ étudiés par Kang Soohyun en 
témoignent. Cette quête de la nature s'accompagne d'une valorisation des jardins, véritables « recours pour habiter la nature » d'après Yves Luginbühl. Le phénomène est important en Asie (cf. les articles de Toriumi Motoki, Kioka Nobuo et Higuchi Tadahiko) mais pas seulement. Augustin Berque, Tanaka Hidemichi, Wu Juanyu et Gijs Wallis de Vries nous expliquent comment l'ermitage paysager asiatique influence le jardin paysager européen au XVIII ${ }^{e}$ siècle puis comment ce modèle gagne l'Amérique du Nord. L'un des intérêts de l'ouvrage est de mettre en évidence ces transferts culturels même si chaque aire géographique conserve ses particularismes. L'étude des représentations est également importante. Daniel Pinson analyse comment la peinture de Cézanne a influencé la perception d'Aix-en-Provence. S'appuyant sur l'œuvre de Robert Doisneau, Jacques Van Waerbeke envisage "l'arbre en banlieue en tant que métaphore [...] de l'énergie vitale des gamins de banlieue ». De son côté, Tsuchiya Kazuo montre comment à Okitsu, un lieu de villégiature japonais à la mode dans la première moitié $\mathrm{du} \mathrm{XX}^{\mathrm{e}}$ siècle, on choisit de construire sa villa sur le modèle d'une fameuse peinture de Sesshû représentant le mont Fuji.

2 Le phénomène de la ville-campagne s'est accompagné d'un fort étalement urbain. Afin de mieux cerner ce dernier, Maïté Clavel réfléchit en terme de périurbain tandis que Catherine Bidou-Zachariasen et Frédéric Leriche abordent le thème de la ville postfordiste et que Nadine Cattan et Sandrine Berroir rappellent l'influence de la centralité en Europe. Il s'agit également de dater le phénomène. Le cas japonais est bien documenté avec les études de Guillaume Caré, Higuchi Tadahiko, Chiba Masatsugu, Yokohri Makoto et Marco Amati. La réflexion porte également sur les causes de l'étalement urbain : l'attachement des Américains à la maison individuelle (cf. l'article de Cynthia Ghorra-Gobin), le recul des outils traditionnels de la planification en Italie (cf. Maria Cristina Gibelli), les aides publiques à l'accession à la propriété et aux infrastructures routières en Amérique du Nord (cf. Owen Gutfreund et Guy Mercier), le recul des terres agricoles (cf. Alain Suberchicot), etc. Les tensions liées à l'étalement urbain sont également bien mises en évidence avec les contributions de Jean-Pierre Traisnel, Liette Gilbert et Greg Hise. Incontestablement, cet ouvrage offre une grille de lecture très neuve sur le changement le plus important qu'ait connu l'habitat depuis la fin de la seconde guerre mondiale.

INDEX

Mots-clés : ville insoutenable

\section{AUTEUR}

HÉLĖNE HARTER

Hélène Harter est maître de conférences à l'université Paris I 